\title{
Periodismo en la Audiencia de Quito: seis iluminados en la historia del periodismo de Ecuador
}

\author{
María Isabel Punín LARREA \\ Universidad Técnica Particular de Loja (Ecuador) \\ mipunin@utpl.edu.ec \\ Ketty Daniela CALVA CABrerA \\ Universidad Técnica Particular de Loja (Ecuador) \\ kdcalva@utpl.edu.ec
}

Recibido 26 de noviembre de 2013

Aceptado: 21 de mayo de 2014

\begin{abstract}
Resumen
La historia del periodismo en Ecuador inicia con la publicación de Primicias de la Cultura de Quito (1792), periódico que entre otras cosas buscó difundir la cultura y literatura de los ecuatorianos de aquel entonces. El periodismo ecuatoriano está marcado por la presencia de Eugenio Espejo, una de las grandes mentes en la historia del Ecuador; junto a él, anotamos a otros hombres trascendentales: Fray Vicente Solano, Juan María Montalvo Fiallos, Manuel de Jesús Calle Pesantes, Benjamín Carrión Mora y Alejandro Carrión Aguirre, puntuales del empuje intelectual de las sociedad ecuatoriana. El presente artículo evidencia la influencia que su pensamiento tiene en el periodismo de la época, cimiento del ejercicio periodístico en la actualidad.
\end{abstract}

Palabras clave: historia, medios de comunicación, periodismo, prensa escrita, Ecuador

\section{Journalism in the Audiencia of Quito: Six lighted in the history of journalism in Ecuador}

\begin{abstract}
The history of journalism is Ecuador commences with the publication of the Early Culture of Quito (1792, official translation), a newspaper, which, among other things, disseminated the culture and literature of Ecuadorians from that period. The Ecuadorian journalism is strongly marked by the presence of Eugenio Espejo, one of the great minds of the Ecuadorian history. In addition, we could mention other writers of great renown such as Fray Vicente Solano, Juan María Montalvo Fiallos, Manuel de Jesús Calle Pesantes, Benjamín Carrión Mora and Alejandro Carrión Aguirre, all of whom serve as key examples of the intellectual and cultural Ecuadorian life. This paper shows the influence of Ecuadorian thought of the aforesaid era, which helped to pave the way for contemporary Ecuadorian journalism.
\end{abstract}

Keywords: history, media, journalism, newspapers, Ecuador

\section{Referencia normalizada}

PUNÍN LARREA, María Isabel y CALVA CABRERA, Ketty Daniela (2014): "Periodismo en la Audiencia de Quito: seis iluminados en la historia del periodismo de Ecuador". Estudios sobre el Mensaje Periodístico. Vol. 20, Núm. 2 (julio-diciembre), págs.: 1177-1194. Madrid, Servicio de Publicaciones de la Universidad Complutense.

Sumario: 1 Introducción. 2. El primer periódico ecuatoriano y Eugenio Espejo. 3. Vida, principales obras y pensamiento de conocidos periodistas y literarios ecuatorianos; 3.1. Eugenio Francisco Javier de Santa Cruz y Espejo (1747-1795), fundador del periodismo en Ecuador; 3.2. Fray Vicente Solano Machuca (1791-1865), instaurador del periodismo en Cuenca; 3.3. Juan Montalvo Fiallos (1832-1889), opositor del régimen Garciano; 3.4. Manuel de Jesús Calle Pesantes (1866-1908), defensor de la doctrina liberal; 3.5. Benjamín Carrión (1897-1979), fundador de la Casa de la Cultura Ecuatoriana; 3.6. Alejandro Carrión (1915-1992), defensor del socialismo. 4. Conclusiones. 5. Referencias bibliográficas. 


\section{Introducción}

La lucha por una prensa libre en Ecuador se inicia en el año 1869, cuando Gabriel García Moreno asume por segunda vez el mando presidencial; la Asamblea Constituyente de ese año dictó una nueva Carta Fundamental. El Art. 102 de la citada constitución habla sobre la libertad de pensamiento, resaltando que si la prensa faltara el respeto a la moral, la religión o la decencia, los responsables serían castigados según las leyes y por los jueces comunes, artículo que es la semilla de los fundamentos que entorno a la libertad de expresión existen en el país.

Este artículo pretende difundir la vida y obra de los principales personajes ilustres que han apoyado a la lucha por una prensa libre, y como tal son pilares fundamentales del periodismo ecuatoriano. Periodistas y literatos de oficio que han dejado su huella en la historia a través de publicaciones-obras que trascienden y hacen eco de la lucha libertaria desde finales del siglo XVIII hasta los últimos años del siglo XX.

\section{El primer periódico ecuatoriano y Eugenio Espejo}

Los ecuatorianos del siglo XVII no sabían leer ni escribir, por tal razón, entre otras formas, la expresión oral era su principal medio de comunicación e intercambio de infor-

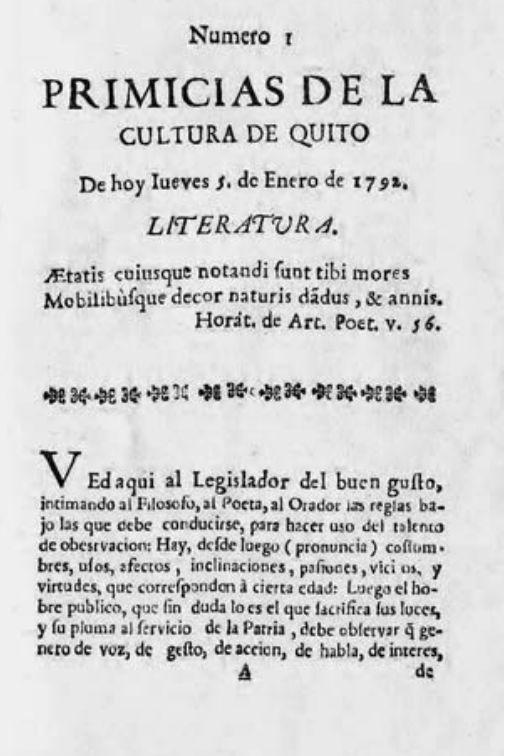

Imagen 1. Portada del primer número de Primicias de la Cultura de Quito de Eugenio Espejo. Fuente: Biblioteca Ecuatoriana Aurelio Espinoza. mación. "Los pueblos andinos no desarrollaron escritura, pero usaron eficientes mecanismos de comunicación como la música y los quipus" " (Ayala, 2012: 3). Es en el siglo XVIII, antes del primer periódico ecuatoriano, cuando se daban otras formas de comunicación; era común el pasquín ${ }^{2}$, pero sobre todo los comunicados en las Iglesias.

Como buena parte de los religiosos eran de las pocas personas alfabetas, su concurso era indispensable para leer no solo la literatura religiosa, sino las normas y disposiciones coloniales... el mercado, era un centro en el que no solo se intercambiaba mercaderías, sino también noticias e información. (2012: 4).

En 1750 se establece la primera imprenta en el Ecuador, propiedad de los Jesuitas. Antes de ello, el único medio con el que contaba el pueblo para manifestarse era el escrito en pared. Eugenio Espejo basándose en esta realidad y al ver que México, Guatemala y Perú ya contaban con periódicos pensó que la capital Quito debía publicar su primer periódico, y así lo hizo.

${ }^{1}$ Sistema de cuerdas anudadas que servían para que los quipucamayos recordaran el mensaje o los hechos; información que se llevada de un pueblo a otro.

2 Escrito que durante las noches se depositaba por debajo de las puertas en los hogares. 
A finales de 1791, Eugenio Espejo prepara a los quiteños con la publicación de un folleto titulado Instrucción Previa, base fundamental del primer periódico del Ecuador.

El 5 de enero de 1792 en la Real Audiencia de Quito, con el apoyo de la Sociedad Patriótica de Amigos del País ${ }^{3}$,aparece con periodicidad quincenal bajo el nombre de Primicias de la Cultura de Quito, el primer periódico en la historia del periodismo ecuatoriano: “...era un periódico exclusivamente literario. Se editaba en la imprenta de Raimundo Salazar, con licencia del Superior Gobierno" (Ceriola, 1909: 6).

Según afirma Ceriola (1909), a través de este acontecimiento, Espejo contribuyó a dar gloria y renombre a su patria. Luego de Primicias los quiteños (indios y mestizos) buscaron más que conocimientos religiosos y otros aprendizajes comunes de la época, su deseo de lucha y libertad cada día crecía más. Desde el año 1792 hasta inicios del siglo XX existieron alrededor de 1000 medios (Rolando, 1920) unos con características literarias y culturales; otros con características políticas y electorales. Periodistas y literatos pugnaban por una prensa que permitiera expresar libremente sus sentimientos contradictorios ante las ideologías de los gobiernos de curso: “...el hombre ecuatoriano siempre vibró cuando se trataba de luchar por su dignidad atropellada" (García, 1979).

Entre estos personajes de ideología destacada se encuentran: Eugenio Francisco Javier de Santa Cruz y Espejo (1747-1795), admirable médico ecuatoriano, de ideología liberal y precursor que fundó el primer periódico ecuatoriano; Fray Vicente Solano (1791-1865), defensor de la obra del Libertador Simón Bolívar e instaurador del periodismo en Cuenca a través de la publicación El Eco del Azuay; Juan María Montalvo Fiallos(1832-1889), ferviente opositor al Garcianismo y toda forma de dictadura y fundador de El Cosmopolita, publicación de carácter político; Manuel de Jesús Calle Pesantes (1866-1908), difusor de la doctrina liberal y fundador del periódico $L a L i$ bertad, medio basado en la crítica y la denuncia; Benjamín Carrión Mora (1897-1979), promovió la educación como pilar fundamental para el desarrollo del país, y fundador de la Casa de la Cultura Ecuatoriana-CCE; y, Alejandro Carrión (1915-1992), luchador que promovió el socialismo y fundador de la revista de la CCE.

\section{Vida, principales obras y pensamiento de conocidos periodistas y literarios ecuatorianos}

\subsection{Eugenio Francisco Javier de Santa Cruz y Espejo (1747-1795), fundador del periodismo en Ecuador}

El 21 de febrero de 1747, nace en Quito el periodista, médico, político, filósofo, investigador, escritor, bibliotecario, abogado y pensador de origen humilde, Eugenio Espejo. Sus padres fueron Luis Santa Cruz y Espejo y María Catalina Aldás Larraincar. Eugenio, un mestizo que por su posición social estaba destinado a ser un artesano o cirujano común, se educó por las enseñanzas de su padre y luego en el Colegio Se-

${ }^{3}$ Se fundó el 30 de noviembre de 1791 con la finalidad de atender los problemas que enfrentaba la Real Audiencia de Quito, entre ellos la educación, las ciencias, las artes, la agricultura, el comercio, la economía y la política. Eugenio Espejo fue su secretario. En un inicio era conocida como la "Escuela de la Concordia". Los estatutos fueron expedidos por el Rey Carlos III de España 
minario Real de San Luis, institución de los Jesuitas. En este colegio mantuvo una convivencia difícil debido a la discriminación de sus compañeros; a pesar de sus excelentes calificaciones fue tachado con la burla. Al referirse a esa terrible época de su vida, su biógrafo Marco Chiriboga escribió:

.... la edad de 15 años deseó ardientemente ser conocido por bello espíritu y aunque logró las celebridades de los jesuitas, el vulgo lo despreció, por lo que, tomando opuestos dictámenes, se ocultó lo más que pudo y así ha conseguido el arte de esconderse, de tal suerte que ha logrado ventajosamente que se piense muy mal de sus alcances, conocimiento y literatura (Chiriboga, 2009: 69).

Eugenio Espejo obtuvo el título de maestro en filosofía con las más altas calificaciones en la Universidad Real y Pontificia de San Gregorio el 8 de junio de 1764. También estudió en la Universidad de Santo Tomás de Aquino, institución de los Dominicos, fundada en Quito en el año de 1681. Desde 1752 regía una disposición de la corona española que constaba dentro de los requisitos para ingresar en dicha Universidad: “...en las universidades de América no se matriculen a individuos que no estuviesen en capacidad de certificar la legitimidad y limpieza de su sangre. La ley también excluía a quienes no estaban en capacidad de probar que en varias generaciones habían sido reputados por limpios, cristianos, y sin mezcla en su sangre de judío, moro o converso" (Chiriboga, 2009: 108-109). A pesar de ello, Luis, padre de Espejo, logra que su hijo ingrese a Facultad de Medicina y obtenga su título en junio de 1767. También estudió Jurisprudencia y teología y terminó las dos carreras en 1770.

Eugenio Espejo siempre estuvo movido por sus pasiones, anhelaba encontrar siempre la verdad y promovía la justicia. A pesar de ello odiaban a Espejo los funcionarios españoles y hasta una buena porción de su propio pueblo, por considerarlo un herético y un prosélito de las "impiedades de la Revolución Francesa". Pero en el fondo Espejo no era sino un crítico veraz del atraso de su tiempo, del desenfreno materialista del clero, de la incapacidad para gobernar que demostraban muchos, y de la evidente inutilidad del monarquismo europeo para América. (Reyes, 1984: 368).

Tuvo muchos enemigos por sus ideas plasmadas en sus publicaciones. Por ello tuvo que enfrentarse a varios juicios en su contra: "fue perseguido por los Presidentes de la época, en sucesión, y a partir de José García de León y Pizarro4, Juan José Vi1lalengua y Marfilis. Hasta Luis de Guzmán Montero de Espinosa, se encargarían de perseguirlo" (Chiriboga, 2009: 118).

Espejo "tenía que rebelarse contra la inopia del ambiente, contra la absurda desigualdad a que estaban condenados los americanos y sobre todo los mestizos y los indígenas, contra la autoridad arbitraria, y, finalmente contra las ideas caducas de este tiempo" (Barrera, 1979: 311). Eugenio Espejo y otros muchos quiteños estaban cansados de las irregularidades, abusos y corrupción del gobierno de José García de León y Pizarro, español oriundo de Sevilla: “....además de ser Presidente, Regente, Gober-

4 Español que fue Presidente de la Real Audiencia de Quito, tomando el mando el 23 de noviembre de 1778.

5 Español, yerno de León y Pizarro y sucesor del gobierno de la Audiencia, asumiendo su cargo el 4 de mayo de 1784. 
nador y Capitán General de la Audiencia, había sido nombrado Visitador de la Real Hacienda y Tribunales de Justicia" (Chiriboga, 2009: 195). García de León llegó al país envestido de poderes e inicia sus funciones el 8 de julio de 1767.

En 1779 nace El Nuevo Luciano o Despertador de los ingenios quiteños, en nueve conversaciones eruditas para el estímulo de la literatura, su primera obra, inspirada en la ignorancia en la que vivían los quiteños de aquella época:“...denunciaba los atropellos y estado de postración en que se encontraban todas y cada una de las estructuras coloniales: desde la cultural y educativa, pasando por la económica o política hasta desembocar incluso en la religiosa, que también fondeaba por varios costados" (Paladines, 2010).

Pronto la obra causó revuelo y más aún por el desconocimiento del nombre de tan atrevido autor -Espejo lo firmó bajo el nombre de Javier de Cía Apéstigue y Perochena-. En 1780 aparece en la capital de la Audiencia el libro Marco Porcio Catón, o Memorias para la impugnación del Nuevo Luciano de Quito, bajo el seudónimo de Moisés Blancardo: "El libro presenta una dedicatoria al Ilustrísimo Obispo de Quito, Don Blas Sobrino y Minayo, y luego se dirige al Lector" (Chiriboga, 2009: 237). Ese mismo año publica la Ciencia Blancardina, libro inspirado en aquellos frailes que ostentaban exagerada sabiduría.

El 11 de noviembre de 1785, y por órdenes del Cabildo (para la fecha el nuevo presidente de la Audiencia era Juan José Villalengua- yerno de García Pizarro), Eugenio publica el voluminoso libro de 350 páginas Reflexiones sobre la utilidad, importancia y conveniencias que propone Don Francisco Gil, Cirujano del Real monasterio de San Lorenzo, y su sitio, e individuo de la Real Academia de Madrid, en su disertación físico médica, acerca de un método seguro para preservar a los pueblos de las Viruelas: “...la obra que a más de sus indudables méritos en relación con el surgimiento de la medicina social en América Latina, incluía una serie de inevitables ataques, en particular contra los médicos y betlemitas, los que reaccionaron violentamente, profundizándose el encono en contra de Espejo entre otros sectores"(Valdano y Albán, 2001: 203). En el libro, Espejo también hace crítica y denuncia la política y el entorno social: "estas aseveraciones, que en el fondo fueron críticas a la situación de aquel entonces, sirvieron de pretexto a algunos médicos quiteños y a la comunidad de los frailes Bethlemitas, para que condenaran el texto de Espejo, bajo la argucia que en sus páginas se habían proferido calumnias en su contra" (Rodas, 2010: 2).

Espejo llegó a Riobamba para defender a los sacerdotes de Ignacio Barreto, quien se desempeñaba como Alcalde Ordinario y Comisionado principal de la Real cobranza de tributos: "...les acusaba de varios abusos para sonsacar el dinero a los indios..." (Paladines, 2007: 44). A pesar de que sus fundamentos estaban muy bien planteados en la Defensa de los curas de Riobamba (1786), “...de todos modos, la situación de repudio contra su persona se profundizó una vez más y en particular por la circulación de unas Cartas Riobambenses ${ }^{6}$ (1787) que dejan interesantemente pintadas las tertu-

6 Se las puede encontrar en la Biblioteca Virtual Miguel de Cervantes. http://www.cervantesvirtual.com/ 
lias de la época y que motivaron un juicio por injurias" (Albán, 2001: 203). Dichas cartas son una serie de 8 artículos a través de los cuales denunció la corrupción y mala vida que se llevaba en Riobamba.

Estos conflictos de Riobamba lo llevarían por primera vez a prisión: “...esto ya en pleno año de 1787, Espejo fue enjuiciado por las supuestas graves calumnias, en medio del beneplácito de sus enemigos, lo cual trajo como resultado su apresamiento y encarcelamiento y su posterior traslado, en condición de preso, a Quito" (Rodas, 2010: 3).

Fue tres veces encarcelado, primero por José García de León y Pizarro; la segunda vez por Juan José Villalengua; y, la tercera vez, bajo la presidencia de Muñoz de Guzmán. Por esta tercera detención fue destituido de la Biblioteca Pública`de la que era director. Lo llevaron a una precaria celda en donde vivió los últimos meses de su vida: “...era tan malsano el ambiente que enfermó de gravedad, posiblemente de amebiasis, se puso tan grave que el 20 de diciembre le dejaron salir a la casa en el Mesón donde vivía con su hermana..." (Pérez, 2001). Murió el 27 de diciembre de 1795.

\subsection{Fray Vicente Solano Machuca (1791-1865), instaurador del periodismo en Cuenca}

Domingo Solano Vargas Machuca fue escritor cuencano que nació en 1791, hijo de agricultores, Tomás Solano y María Vargas Machuca. Vino al mundo en años de poco acceso a la educación. Sus primeros conocimientos los adquirió por su padre. En 1800 viaja a Quito al Convento San Francisco y sobresalió como estudiante de filosofía. En 1814 obtiene la ordenación sacerdotal con el nombre de Fray Vicente.

Para Fray Vicente, quien promovía la prensa con un pensamiento libre, el periódico será "el principal instrumento para la difusión de ideas y su arma de combate, porque Solano es uno de los polemistas de mayor fuste y más temibles de los que ha producido el país" (Barrera, 1979: 654-655).

Cuando Ecuador se establece como República (1830) no se generan cambios positivos. Sus primeros presidentes Juan José Flores, Vicente Rocafuerte y Ramón Roca cometieron errores de gobierno, desde la falsificación de moneda ${ }^{8}$ hasta la generación de la temida Carta de la Esclavitud": “...esto es lo que hereda: ningún desarrollo cultural, pobreza humanística, una educación impositiva dada por frailes, curas y monjes; escasa atención al desarrollo artístico y plástico...” (Rivera, 2012: 119). La prensa se desarrolla en medio de este panorama que no era nada prometedor:

En las páginas de los periódicos se informaba sobre la labor de los poderes del estado, se los defendía o criticaba, se lanzaban candidaturas o se las combatía, se presentaba de-

7 Fue creada bajo el Gobierno Interino de Juan Antonio Mon y Velarde. La atención al público inició el 25 de mayo de 1792 “... con la fama de ser la más completa de América en casi todas las materias"(Chiriboga, 2009: 435)

8 En aquel entonces circulaba la moneda granadina, oriunda de Colombia que estaba contramarcada con las iniciales M.D.Q.

9 Entre enero y junio de 1843 con orden del General Flores se redacta una carta política que limita los derechos y libertades de los ecuatorianos, en dicho escrito se permitía que Flores fuera Presidente de la República de forma indefinida. 
nuncias y acusaciones, se publicaba documentos probatorios o exculpatorios, se insertaba aclaraciones, se promovía obras públicas, servicios e iniciativas fiscales. (Ayala, 2012: 7).

La imprenta llega a Cuenca en 1827, aproximadamente 70 años después de la primera imprenta en Ambato. Solano, con el beneficio de tener bajo su responsabilidad la única imprenta de Cuenca, inicia el periodismo cuencano el 1 de enero de 1828 al fundar El Eco del Azuay, publicación que motivó elogios de Simón Bolívar, quien mostraba el buen concepto que tenía de Fray Vicente al exhibirse con interés leyendo sus publicaciones. En El Eco del Azuay se encontraban escritos de Solano que iban desde la política y la ciencia hasta la filosofía y la religión y, a través de ellos, defendió la libertad de imprenta. Se lograron publicar 26 números. "El formato del periódico es infolio, consta de cuatro páginas á dos columnas, de edición bastante clara y limpia, en el antiguo papel conocido como San Lorenzo" (Ceriola, 1909: 19)

En 1829 fundó los periódicos El Telescopio y La Aforja que se basaban principalmente en batallar contra la invasión del Perú, expedición promovida por el Mariscal La Mar ${ }^{10}$ : "La Mar no sacó sino la vergüenza de la derrota, y el destierro, después" (Barrera, 1979: 655).

Su primer libro fue La Predestinación y reprobación de los hombres, según el sentido genuino de las escrituras y la razón (1828), “...que sufrió un sin fin de avatares, a tal extremo que mereció la censura eclesiástica por herético y la condenación de la Iglesia romana" (Araujo, 2002: 146). La lectura de este libro fue prohibida por el Papa Pio IX quien también ordenó la inclusión de la obra en el índice de libros prohibidos por la iglesia en 1857.

Entre los logros de Fray Vicente Solano destaca la publicación del Semanario Eclesiástico, “...fundado en 1835 , tenía por objeto salir a la defensa de los principios católicos atacados por El Ecuatoriano del Guayas..." (Ceriola, 1909: 21). A través de dicho periódico luchó contra las ideas vanguardistas del decreto de exclusión a los sacerdotes en la convocatoria para elecciones para Diputados a la Asamblea Constituyente. La publicación de este periódico lo llevó a vivir constantes polémicas: con el Coronel Francisco Eugenio Tamaríz, político español, que para el año 1835 se des-

${ }^{10}$ Político y militar cuencano que nace el 12 de mayo de 1776, fue nombrado Comandante General de Armas de la provincia de Guayaquil; participó en la Batalla de Pichincha del 24 de mayo de 1822; entre otros logros militares en Europa y América del Sur. 
empeñaba como Ministro de Hacienda en Guayaquil; con el Dr. Salvador Jiménez, Obispo de Popayán; con Antonio José de Irisarri, guatemalteco erradicado en Chile, lugar donde entre otras labores desempeñó como Ministro de Interior y Relaciones Exteriores; y con el Dr. Mariano Veintimilla, Provisor y Vicario Capitular del Obispado de Cuenca.

Uno de sus importantes trabajos es la publicación periódica de La escoba, “...el último y más importante de los periódicos que publicó" (Ceriola, 1909: 59), fundado en 1854 , “... aunque con algunas interrupciones, duró cerca de cuatro años y tenía por objeto barrer las inmundicias de La Libertad (periódico que se publicaba en Quito)" (Ceriola, 1909: 59).

Muchos de sus conocimientos en botánica y otras ciencias se vieron reflejados en sus libros: Viaje a Loja y Segundo Viaje a Loja (1848): “....realizó diferentes recorridos a la provincia de Loja, con el intento de observar las especies de quina, los minerales y los animales de la zona y las condiciones del aire y del agua. Además, numeró las plantas que podrían servir para fines medicinales con su nombre vulgar y técnico..." (Paladines, 1996: 88). Los dos viajes a Loja los realizó al ser nombrado rector del Colegio de Loja ${ }^{11}$, institución fundada en 1727 y considerado el primer y único Colegio de Jesuitas en Loja. "Loja tuvo la categoría de ciudad favorecida entre las contadas que gozaban en la colonia, el privilegio de tener Colegio y Escuela de primera calidad" (Jaramillo, 1982: 220). El colegio se quedó en un periodo de silencio debido a la expulsión de los jesuitas en 1767: “...fueron expulsados de América Hispánica, por la Real Cédula de Carlos III, Rey de España” (Jaramillo, 1982: 220). Los motivos fueron la acumulación de riquezas de la que presumía la Compañía de Jesús:

“...la enormidad de sus acumulaciones territoriales y de riquezas en general, el exceso de sus influjos sociales y políticos, y la secreta pugna alentada contra las ideas liberales de que venía presumiendo "el despotismo ilustrado" de ciertos monarcas de la época, provocaron los recelos y la hostilidad contra la Compañía de Jesús” (Reyes, 1984: 99).

Gracias a las labores filantrópicas del impulsor de la educación en el Ecuador, Bernardo Valdivieso, que en aquel entonces cumplía su labor de Regidor del Cabildo de Loja, se retomó la educación secundaria para los jóvenes lojanos y en 1826 se pudo al fin instalar el "Colegio San Bernardo", así llamado en el nuevo Reglamento, y desde este hecho ha quedado el siguiente documento: "En veintidós de Octubre de mil ochocientos veinte y seis, en la Iglesia de las Religiosas Conceptas se anunció la instalación del Colegio de San Bernardo en esta ciudad de Loja...(Gallardo, 1977: 33).

En 1851 Vicente Solano publicó La Guerra Catilinaria de Salustio, considerada como una de las obras más importantes dentro de la política y la moral de la época: "Véase por qué he resuelto traducir esta obrita, y presentarla al pueblo americano

${ }^{11}$ Actualmente se llama Colegio Bernardo Valdiviezo. En sus inicios logró varios obstáculos políticos y económicos, enalteciendo su misión cultural en Loja. "El Gobierno Federal de Don Manuel Carrión Pinzano se acentúa en la obra educativa, el Colegio de San Bernardo, que mantenía la tradición cultural de Loja, incorpora en su organización la Facultad Mayor que comprendía los primeros cursos universitarios " (Gallardo, 1977: 34) 
como un libro elemental, para la conducta de los gobernantes y gobernados. Aquí aprenderán a conocer á los hipócritas que, como Catilina, no dejan de pronunciar las palabras libertad, patria, opresión, etc., para aniquilar la república y elevarse sobre su ruina" (Solano, 1851: web)

Fray Vicente Solano murió en Cuenca el 1 de abril de 1865, enfermo de amebiasis. Hoy se lo recuerda como "...el escritor polígrafo por excelencia y como tal, un conductor de la cultura azuaya..." (Araujo, 2002: 150).

\subsection{Juan Montalvo Fiallos (1832-1889), opositor del régimen Garciano}

Juan Montalvo Fiallos, ambateño, nació el 13 de abril de 1832. Sus padres fueron Marcos Montalvo Oviedo y María Josefa Fiallos y Villacreses. Estudió Gramática Latina en el convictorio San Fernando en Quito hasta el año 1848, cuando pasó al seminario de San Luis, colegio que desde su fundación en 1594 por Fray Luis López de Solís estuvo administrado por la Compañía de Jesús. Durante 173 años los jesuitas dirigieron el Seminario de Quito que llegó a llamarse Colegio Mayor, Real y Seminario de San Luis. A raíz del Real Decreto del Carlos III de expatriación de los jesuitas y ocupación de sus temporalidades (20 de agosto de 1767), el Colegio Seminario pasa a manos de la Santa Iglesia Catedral cuyo Obispo fue Pedro Ponce y Carrasco (Piñas. 2008: 3). En el Seminario de San Luis obtuvo su grado en Maestro de Filosofía. Con muy poco interés también hizo estudios en Jurisprudencia.

En 1852 fue miembro de la Sociedad Liberal "La Ilustración". Esta sociedad estaba dirigida por Miguel Riofrío y formaron parte de ella J. Montalvo y su hermano Francisco. Contó con destacados personajes de la historia del Ecuador, entre ellos, Eugenio Espejo y Fray Vicente Solano. "La Ilustración conformó el ideario político de la mayoría de los guerreros de la emancipación, pero también de los ideólogos y constructores de las nuevas repúblicas. Los ilustrados escribieron su filosofía como respuesta al reto de independizar América de España..." (Paladines, 1991: 19). Perseguían el desarrollo del país, difundiendo la educación, la cultura y la literatura. Este fue un periodo intelectual que promovía el liberalismo:

“...comenzó a invocarse varias décadas antes de que se conformase la República del

Ecuador y que, sin embargo alcanzó su clímax de maduración en los mismos días en que emergía la nueva entidad, se prolongó, a través de políticos y pensadores ilustrados, a las primeras décadas de la organización del flamante estado, y llegó a plantear preguntas y dificultades aun al hombre de las postrimerías del siglo XX (Paladines, 1991: 21).

El 17 de octubre de 1868 contrajo matrimonio María Guzmán Suárez, costurera de profesión, con quien tuvo dos hijos. "Cultivó todos los géneros literarios, hizo poesías, periódicos, panfletos, novelas, cuentos y dramas para teatro, pero sobre todo brilló como ensayista por su erudición clásica y belleza en la forma literaria" (Pérez, 2001: 254). Además de sus dotes de escritor y periodista, destacó también por su lucha por las libertades de los ecuatorianos:

"Fue un hombre perpetuamente insatisfecho, desengañado; las pequeñeces del medio, la hipocresía en lo político y en lo religioso, los subterfugios, las trapacerías encendían su ira volcánica, justiciera, pero incontrolable" (Ayala, 1990: 95). 
Montalvo huyó por temor a Panamá -donde conoció a Eloy Alfaro-, cuando en julio de 1869 se desatara la revolución Garciana con un referéndum que expide la octava constitución del país, actualmente conocida como la Carta Negra ${ }^{12}$. Fundó en 1876 la revista política y literaria El Regenerador que “....contiene una colección de artículos que no son de periódico, sino ensayos literarios..." (Barrera, 1979: 742). En esta revista, con tendencia de oposición, se publicaron 12 números hasta el año de 1878. Y en enero de 1886 fundó su mayor obra periodística, El Cosmopolita, que en su prospecto decía: "Mucho es que ya podamos al menos exhalar en quejas la opresión en que hemos vivido tantos años; mucho es que no hayamos quedado mudos de remate a fuerza de callar con fuerza; mucho es que el pensamiento y las ideas de los ciudadanos puedan ser expresadas y oídas por los ciudadanos" (Villavicencio, 1977:108).

En El Cosmopolita Juan Montalvo emprendió su lucha contra el gobierno de García Moreno a quien siempre mantuvo encabezando su lista de hombres no gratos, sobre todo porque consideraba que era el primer enemigo de la civilización ecuatoriana:

"Más el paréntesis de su libertad duró muy poco. García Moreno, con un golpe de audacia y felonía, retornó al poder y Montalvo tuvo que tomar el camino de un largo destierro" (Naranjo, 2006: 13).

Por sus constantes reivindicaciones de las libertades públicas, Montalvo pasó mucho tiempo de su vida exiliado del Ecuador. Durante su primer destierro desde Ipiales-Colombia se decide a escribir la Dictadura Perpetua, obra que empezó a circular en el Ecuador en 1875, “...frontalmente dirigida contra García Moreno, tuvo, con certeza, un papel importante en la preparación del atentado que finalmente eliminó al presidente del panorama político del país" (Ayala, 1990: 96). El libro hablaba de la dictadura y gobierno del tres veces Presidente del Ecuador Gabriel García Moreno. Se lo llamó "libro prohibido" debido a que por orden de García Moreno "la policía perseguía al folleto y lo comisaba, pero las copias se multiplicaban misteriosamente" (Villavicencio, 1977: 133). Juan Montalvo murió en París el 17 de enero de 1889

\begin{tabular}{|l|c|}
\hline \multicolumn{1}{|c|}{ Tabla 1. La actividad política e intelectual de Juan Montalvo } & AÑO \\
\hline Fundó el periódico La Razón & 1848 \\
\hline Fundó el periódico El Veterano & 1849 \\
\hline Miembro de la Sociedad Liberal "La Ilustración” & 1852 \\
\hline Fue electo Secretario de San Fernando & 1853 \\
\hline Fundó el periódico La Moral evangélica & 1854 \\
\hline Fundó el periódico El Espectador & 1855 \\
\hline $\begin{array}{l}\text { Fue designado Adjunto Civil de la legislación en Roma y viajó a Europa con el } \\
\text { Secretario Francisco Xavier Salazar. }\end{array}$ & 1857 \\
\hline Colaboró con la revista literaria El Iris. & 1861 \\
\hline Publicó El Cosmopolita. & 1866 \\
\hline
\end{tabular}

${ }^{12}$ Se la llamó así porque de entre otras barbaridades, se declaraba que desde el poder ejecutivo partía cualquier actividad política; como también declaraba que para ser ciudadano, como requisito se debía ser católico. 


\begin{tabular}{|l|c|}
\hline Publicó El Precursor del Cosmopolita. & 1867 \\
\hline Escribió Los capitulos que se le olvidaron a Cervantes. & 1871 \\
\hline Del orgullo y de la mendicidad, Fortuna y Felicidad, El Antropófago. & 1872 \\
\hline Publicó Judas. & 1873 \\
\hline La Dictadura Perpetua & 1874 \\
\hline El Último de los Tiranos, Editó el periódico La voz del Norte. & 1875 \\
\hline Del Ministro del Estado. & 1876 \\
\hline Las Leyes de García Moreno, El Regenerador, El León de San Marcos, Vicente & $1877-1878$ \\
\hline Piedrahita, El Desperezo del Regenerador y Caracteres de los libelistas. & 1879 \\
\hline Editó Los Grillos perpetuos y El Sur de Colombia. & 1880 \\
\hline Las Cinco Primeras Catilinarias y El Heraldo de las Siete Catilinarias. & 1882 \\
\hline La Catilinaria número 12. & 1883 \\
\hline Terminó Los Siete Tratados. & 1884 \\
\hline La Mercurial Eclesiástica. & 1885 \\
\hline Estaba encargado de la revista bimensual Europa y América y editó El Espectador. \\
\hline
\end{tabular}

\subsection{Manuel de Jesús Calle Pesantes (1866-1908). Defensor de la doctrina liberal} Nació en Cuenca el 24 de diciembre de 1866. Realizó sus estudios en el Colegio Seminario de su ciudad natal; del centro de estudios aprovechó completamente los libros de la biblioteca para cultivar conocimientos de la historia y literatura. Durante esta época también comenzaba a formarse en el periodismo, publicando a la edad de 18 años en el periódico "El Pensamiento", sus críticas contra celebridades de su tiempo. Entre los personajes más criticados por Calle están Ignacio de Veintemilla ${ }^{13}$ y Eloy Alfaro ${ }^{14}$.

Manuel de Jesús Calle se casó con Rosa Solano de la Sala ${ }^{15}$, con quien tuvo 7 hijos. Y como luchador logró una de las más altas formas de felicidad: "la satisfacción de cumplir con su deber de hombre, de latinoamericano, de ecuatoriano, de liberal, de trabajador, de amante de la cultura, el derecho, la ciencia; enemigo de todos los enemigos de sus causas" (Muñoz, 1988:57).

En 1888 fundó el periódico La Libertad, a través del cual critica la vida y costumbres cuencanas de la época; en el número 3 escribe lo siguiente: "¿Qué hacer con los gobernantes imbéciles o pícaros, que de todo son capaces menos de una obra buena? Protestar, porque la protesta es propia de la Justicia imponente; del Derecho ofendido en la persona de los débiles; y esperar el día de la reacción, porque la esperanza es la herencia de los libres" (Calle, 1888).

La circulación de La Libertad fue prohibida en Loja por José María Masia y Vidiella, obispo de dicha ciudad, "...y luego por el de Cuenca Miguel León Garrido..." (Pérez, 2001).

${ }^{13}$ Político y militar que durante 1876 y 1883 se desempeñó como Jefe Supremo y Capitán General del Ejército de la República.

${ }^{14}$ Defensor del liberalismo radial, fue designado Presidente de la república por dos periodos que comprenden: 1895-1901 y 1906-1911.

${ }^{15}$ De buena posición social, con gran belleza y una de las propietarias de la cervecería alemana. 


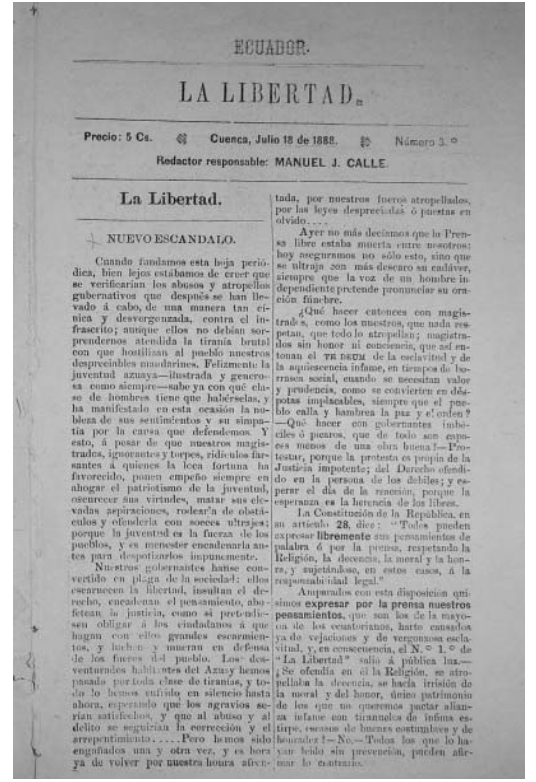

Imagen 3. Portada del tercer número de La Libertad de Manuel. J Calle. Fuente: Biblioteca Ecuatoriana Aurelio Espinoza.

Al año siguiente frustró su deseo de estudiar leyes al publicar Carta Abierta al Ilustrísimo Sr. Obispo Dr. Dn. Miguel Léon, que fue considerado como atrevido y poco respetuoso. En 1891 y al verse acorralado en Cuenca, decide erradicarse en Guayaquil, y en 1892 funda El Intransigente, semanario creado con fines liberales. En esa misma época escribió para El Diario de Avisos y El Tiempo. También editó los siguientes periódicos: El Correo Nacional (1895), en Quito; La Semana Literaria, El Nuevo Régimen (1896-97) y La Revista de Quito (1898). Esta última, semanal, que duró poco tiempo, tuvo características políticas y liberales; además de tener como colaboradores a Luís A. Martínez, Julio Arboleda, Celiano Monge, Nicolás F. López, etc. Al grupo también se suma el diario El Radical (1904), que se escribía en seis columnas y en la Imprenta Nacional.

Murió enfermo de cirrosis el 6 de octubre de 1908. Hoy Manuel de Jesús Calle representa a una personalidad controvertida que a su vez fue "...dictador y esclavo del periodismo" (Crespo, 1988: 17).

\subsection{Benjamín Carrión (1897-1979), fundador de la Casa de la Cultura Ecuato- riana}

Escritor, político, diplomático y periodista que fomentó la cultura en el Ecuador y en el resto de América. Nace en Loja el 20 de abril de 1897. Sus padres fueron Manuel Carrión y Filomena Mora. Contrajo matrimonio con su prima Águeda Eguiguren Riofrío, con quien tuvo dos hijos: Jaime Rodrigo y María Rosa. Estudió el bachillerato en el Colegio Bernardo Valdivieso en su ciudad natal, época que se instruía con lecturas europeas (principalmente la lectura francesa), además de participar de las charlas literarias a cargo del Dr. Pío Jaramillo Alvarado, gobernador de la provincia de Loja en aquel entonces. De esas edificantes conversaciones apareció Vida Nueva, periódico que recogía las realizaciones del grupo de igual nombre y al que pertenecía Carrión que cursaba el cuarto curso. Como director de la publicación figuraba Clodoveo Jaramillo Alvarado y como redactores, además de Benjamín, Manuel José Aguirre y Carlos Manuel Espinoza. (Barriga, 1985: 18). Ya en el año de 1916 forma parte de la Facultad de Jurisprudencia en la Universidad Central del Ecuador y en 1922 consigue su título.

Luego de la batalla de $1941^{16}$, fue uno de los primeros en impulsar el país para levantarlo de aquella caída:

${ }^{16}$ Año que se firma el llamado Tratado de Río de Janeiro, acuerde con el que Ecuador pierde importante cantidad territorial, cediendo sus derechos al río Amazonas y gran parte oriental en beneficio del vecino Perú. 
"La derrota ecuatoriana, en el campo militar se debió a factores que la historia ha puntualizado en su debido momento; ello trajo desmotivación, desgarramientos profundos, desasosiego y frustraciones. En tales circunstancias, se imponía una voz madura y orientadora de la conciencia nacional, hecha trizas por lo indicado. Esa voz fue la de Benjamín Carrión, en sus “Cartas al Ecuador” (Barriga, 1985:104)

Lo hacía también a través de su faceta como docente, indicando a sus alumnos que la educación era una de las principales fortalezas para el desarrollo del Ecuador. Además de haber sido uno de los fundadores de la Federación de Estudiantes Universitarios del Ecuador (FEUE), al mismo tiempo que ejercía la presidencia de la Asociación de la Escuela de Derecho, también colaboraba con la revista de la Facultad y con los periódicos capitalinos, La Caricatura y El Día, donde escribió artículos de corte periodístico y literario. (Handelsman, 2007: 12)

Destacando su eminente defensa de la cultura, fundó la Casa de la Cultura Ecuatoriana $^{17}$ (CCE) en 1944: "De acuerdo a sus estatutos, esta entidad tiene la misión de dirigir, orientar, y preservar las manifestaciones de la cultura nacional, con la misión de impulsarlas espiritual y materialmente" (Barriga, 1985: 59). Carrión fue su primer presidente y promotor del logro. La CCE se convirtió en un ícono de la ciudad de Quito y del país. Desde el comienzo puso énfasis en los museos, bibliotecas y prensa. Publicó la revista Letras del Ecuador bajo la dirección de su sobrino Alejandro Carrión"18, hasta la actualidad dicha publicación presenta artículos de carácter histórico, artístico y literario.

Sus actividades políticas y literarias pronto fueron reconocidas y escuchadas en el continente, por lo que se hace indispensable nombrar sus hazañas más importantes: cónsul del Ecuador en El Havre, puerto francés (1925-1931); secretario de la Legación ecuatoriana en Lima (1931); miembro del Partido Socialista Ecuatoriano(1932); ministro plenipotenciario en Bogotá por el gobierno de Enríquez Gallo (1939); ministro de Educación durante tres meses en el gobierno de Alberto Guerrero Martínez; candidato a la vicepresidencia de la República con Antonio Parra Velasco (1960); reelegido presidente de la Casa de la Cultura Ecuatoriana (1961); Embajador de Ecuador en México (1968); jurado en el Concurso Literario de Casa de las Américas de Cuba (1960); catedrático en la Universidad Autónoma de México (1963); miembro fundador de la Comunidad Latinoamericana de Escritores (1965); jurado del Premio Internacional de Literatura "Rómulo Gallegos Lara" de Venezuela (1967); presidente del Tribunal Supremo Electoral (1978). También obtuvo los siguientes reconocimientos: Premio Único "Benito Juárez" (1968), Premio Nacional de Cultura "Eugenio Espejo" (1975).

${ }^{17}$ Nace como una necesidad de levantar al país tras la guerra de 1941. A través de ella se busca fomentar y proteger la cultura; fortalecer el pensamiento científico, económico y jurídico de los ecuatorianos y cuidar la inspiración artística.

${ }^{18}$ Esta información fue tomada de la página oficial de la Casa de la Cultura Ecuatoriana "Benjamín Carrión”. http://cce.org.ec/index.php?id=1640. Fecha de consulta 8 de julio del 2013. 
Murió en Quito el 9 de marzo de 1979 y tras su muerte la Cámara Nacional de Representantes del Ecuador dio el nombre de Benjamín Carrión a la "Casa de la Cultura Ecuatoriana". Hoy a través de la Casa de la Cultura Ecuatoriana, Carrión sigue forjando su legado de protección a la cultura que da identidad al Ecuador.

\subsection{Alejandro Carrión (1915-1992), defensor del socialismo}

Alejandro Carrión Aguirre nació en Loja el 11 de marzo de 1915. Obtuvo su título de bachiller en Quito en el Instituto Nacional Mejía y se licenció en Ciencias Sociales en la Universidad Nacional de Loja (UNL).

Su estilo se caracterizaba por simplificar sus escritos para que fueran comprendidos claramente por sus lectores. No participaba en eventos sociales para poder ganar tiempo y dejar más obras a la historia del Ecuador. Según Pérez (2001), Carrión dedicaba parte de su tiempo en leer a grandes escritores españoles: Valle Inclán, Gómez de la Serna. De Sudamérica a Rómulo Gallegos, Azuela, Lugones.

En 1945 fundó la revista de la Casa de la Cultura Ecuatoriana y el semanario de literatura Letras del Ecuador "... órgano de la institución de gratísima recordación pues llegó a acreditarse en los medios culturales de Latinoamérica" (Pérez, 2001: 80).

Carrión perteneció al Partido Socialista Ecuatoriano, se estableció como afiliado y participó en huelgas que lo motivaban a escribir poesía revolucionaria. En 1950 abandonó el Partido Socialista y en 1951 fundó la revista de carácter político El Alacrán, en la que pudo manifestarse libremente sin mostrar inclinación hacia ideologías políticas.

Como periodista fue redactor de los principales periódicos y revistas como El Universo y La Razón de Guayaquil, El Sol y El Comercio de Quito y el Diario de las Américas de Miami (EE.UU.). Fue también director de la revista La Calle, de Quito, y redactor de las revistas Vistazo, de Guayaquil, y América, de Washington (EE.UU.) (Avilés, 2013: web).

Los artículos que Alejandro Carrión escribió en diario El Universo al igual que en La Calle eran de carácter político y algunos combatían el Gobierno de Velasco Ibarra: “...con el pseudónimo de Juan sin Cielo, es un escritor político de jerarquía. Novedad de expresión, valentía y firmeza en sus ideas. Artículos realizados con claridad" (Gallardo, 1977: 290). En diario El Universo escribió durante 25 años a partir de 1948.

La Calle nació en 1957 fundada por Carrión junto a Pedro Jorge Vera ${ }^{19}$; era una publicación con estilo agresivo. Uno de los artículos de Juan sin Cielo publicado en el número 123 decía lo siguiente:

"Para predicar con el ejemplo, vuelve a reiterar lo que ya dijera en su número anterior: sus páginas estarán abiertas a todos los impulsos que conduzcan a la unidad, y si hay todavía quien desee seguir blandiendo el garrote como medio de unirnos, ese garrote no será blandido en estas páginas. Aquí estamos, pues, por la unidad a base de que no nos insultemos y lastimemos más aun entre nosotros. Aquí estaremos también para seguir batallando

${ }^{19}$ Cuentista, novelista, poeta, dramaturgo y periodista guayaquileño; trabajó y escribió para importantes periódicos como: El Universo, El Telégrafo y El Mundo de Cuba. 
contra todo el que aspire a impedir la unidad: a ese lo denunciaremos, como a lo que realmente es: cómplice de la Conserva, agente de los «cuervos negros»" (Juan sin Cielo, La Calle, $\mathrm{n}^{\mathrm{o}} 123,18$ de julio de 1959).

Esta y otras publicaciones fueron motivo para que en 1955 Carrión fuera condenado a cuatro días de prisión y una multa por aparente conspiración en contra del gobierno "...incluyendo un bárbaro ataque, al parecer para matarlo, ordenado por un subsecretario del ministerio de Gobierno y un comandante general de la Policía -primos los dos-..."(Vivanco, 2013: web).

Cumplió varias actividades diplomáticas: en la Organización de Estados Americanos OEA, fue seleccionado observador en las elecciones de Bolivia, República Dominicana y concurrió a las Sesiones de Asamblea General de las Naciones Unidas ONU (1966); Jefe de la División de Servicios Editoriales (1971); Jefe de la biblioteca Conmemorativa de Colón (1974); Dirigió el Departamento Editorial de la OEA en Washington (1970), Fue observador de las elecciones en El Salvador (1985).

Alejandro Carrión murió en Quito el 4 de enero de 1992, por un paro cardiaco. La Dirección de Investigación y Cultura del Banco Central del Ecuador publicó sus obras completas, 10 volúmenes, en 1984. Contienen trabajos en prosa y verso de gran exquisitez y sensibilidad conceptual y artística. Su dominio absoluto del idioma le permitió expresarse con los giros más audaces. Su humorismo le daba una agradabilísima conversación. La ironía le prestaba un cierto sarcasmo, aumentando el poder de persuasión de sus textos, amenos y con una cierta gracia transformada fácilmente en sonrisa. (Pérez, 2001)

\section{Conclusiones}

- El origen del periodismo en Ecuador estuvo principalmente en manos de la Iglesia y se caracterizaba por contenidos de carácter político y social. Entre los principales medios de inclinación religiosa están: Semanario Eclesiástico, La Luz, La Civilización Católica, La Voz del Azuay, El Progreso, El Vigía, El Dardo, El Industrial, entre otros.

- Como nacieron también se extinguieron periódicos ecuatorianos. Muchos de ellos se crearon con la necesidad de apoyar a grupos políticos durante las elecciones y luego para combatir a los que llegaban al poder; las inclinaciones más comunes entre los medios eran liberales, afines al gobierno, conservadoras, satíricas y de oposición.

- Los periodistas y literatos, además de la justicia social y política, también se han preocupado por difundir y defender la cultura del Ecuador. Lo han hecho con participaciones en Latinoamérica, por medio de la fundación de instituciones y sobre todo de periódicos y revistas creados con este fin. De esta forma nos dejan el legado de la lucha por un país mejor, un mejor gobierno y un mejor periodismo. 


\section{Referencias bibliográficas}

ARAUJO, Diego (2002): Historia de las Literaturas del Ecuador. Volumen 3. Quito, Universidad Andina Simón Bolívar, Corporación Editora Nacional.

AVILÉS, Efrén (2013): “Carrión, Alejandro". Enciclopedia del Ecuador: http://www.enciclopediadelecuador.com/temasOpt.php?Ind=394\&Let [fecha de consulta 1 de julio del 2013]

AVILÉS, Efrén (2013): "Montalvo, Juan". Enciclopedia del Ecuador: http://www.enciclopediadelecuador.com/temasOpt.php?Ind=1465\&Let [fecha de consulta 1 de julio del 2013]

AYALA, Enrique (1990): Nueva historia del Ecuador. Vol. 8. Quito, Corporación Editora Nacional.

AYALA, Enrique (2012): La Prensa en la Historia del Ecuador: una breve visión general. Quito, Universidad Andina Simón Bolívar.

BARRERA, Isaac (1979): Historia de la Literatura Ecuatoriana. Quito, Libresa.

BARRIGA, Franklin (1985): Benjamín Carrión. Ecuador, Ministerio de Educación y Cultura, Instituto Ecuatoriano de Crédito Educativo y Becas.

CALLE, Manuel (1888): “Nuevo Escándalo”, en La Libertad, Cuenca. (18.07.1888), p.1.

CERIOLA, Juan (1909): Compendio de la Historia del Periodismo en el Ecuador, Guayaquil, Tip. y Lit. de la Sociedad Filantrópica del Guayas.

CRESPO, María Rosa (1988): "Manuel J. Calle Testigo Privilegiado de una Época Conflictiva: Notas para su investigación", en Visión Actual de Manuel J. Calle. Quito, Ilustre Municipalidad de Cuenca, Subsecretaría de Cultura, Fundación Friedrich Naumann, pp. 17-41.

CHIRIBOGA, Marco (2009): Vida, pasión, y muerte de Eugenio Francisco Xavier de Santa Cruz y Espejo. Quito, Impreso en los talleres de NINA Comunicaciones.

GALLARDO, Hernán (1977): 400 años de Cultura Lojana. Editorial Universitaria.

GARCIA, Gabriel (1979): Ensayo sobre la historia de la literatura ecuatoriana. Quito, Imprenta Nacional.

HANDLESMAN, Michael (2007): "Benjamín Carrión”. Colección Pensamiento Fundamental Ecuatoriano. Editorial Ecuador.

JARAMILLO, Pío (1982): Historia de Loja y su Provincia. Segunda edición. Consejo Provincial de Loja.

MUÑOZ, Elías (2008): “Manuel J. Calle y su tiempo", en Visión actual de Manuel J. Calle. Quito, Ilustre Municipalidad de Cuenca, Subsecretaría de Cultura, Fundación Friedrich Naumann, pp. 57-74

NARANJO, Plutarco (2006): “Juan Montalvo". Colección Pensamiento Fundamental Ecuatoriano, Corporación Editorial Nacional. 
PALADINES, Carlos (1991): Sentido y Trayectoria del Pensamiento Ecuatoriano. México, Universidad Nacional Autónoma de México.

PALADINES, Carlos (1996): El Pensamiento Pedagógico Ilustrado. Volumen 1. Quito, Banco Central del Ecuador, Editorial Abya Yala.

PALADINES, Carlos (2007): “Eugenio Espejo". Colección Pensamiento Fundamental Ecuatoriano, Corporación Editorial Nacional.

PALADINES, Carlos (2012): “Eugenio Espejo y el Nuevo Luciano de Quito", en Revista Archipiélago Vol. 16. Num. 58, pp. 19-21:

http://www.revistas.unam.mx/index.php/archipielago/article/view/20225 [fecha de consulta 1 de agosto del 2013]

PÉREZ, Rodolfo (2001): Diccionario Bibliográfico del Ecuador. Tomos 1, 2, 8, 9, Segunda edición. Universidad de Guayaquil.

PIÑAS, Francisco (2008): Inventario del Colegio Seminario San Luis de Quito y sus haciendas durante su secuestro en 1767. Quito, Escuela de Estudios Hispanoamericanos.

REYES, Oscar (1984): Breve historia general del Ecuador. Tomos I y II. Décima cuarta edición. Quito-Ecuador.

RIVERA, Diana (2012): "Breve historia de la prensa en Ecuador. El aporte de Loja", en Revista Latinoamericana de Comunicación Chasqui. Edición septiembre 2012. Número 119.

RODAS, Germán (2010): "Eugenio Espejo y Antonio Nariño: precursores de la ilustración y de la independencia, quienes sellaron su amistad y compromiso en Bogotá". Colombia, IX Congreso Internacional de la Asociación de Historiadores latinoamericanos y del Caribe (ADHILAC): Doscientos años de historia e historiografia de las independencias de América Latina y el Caribe.

ROLANDO, Carlos (1920): Cronología del Periodismo Ecuatoriano PSEUDÓNIMOS de la PRENSA NACIONAL. Guayaquil, Imprenta y Papelería Mercantil-Monteverde \& Velarde.

SOLANO, Vicente (1851): Guerra catilinaria ó La conjuración de Catilina, por Cayo Crispo Salustio, traducida al castellano y anotada por Fr. Vicente Solano. Referido en: BUENO, Antonio (2013): El Espíritu Religioso y Patriótico en la traducción. La Obra De Fray Vicente Solano. España, Universidad de Valladolid: http://www.traduccion_franciscanos.uva.es/precong/pdf/Bueno.pdf [fecha de consulta 4 de agosto del 2013]

VALDANO, Juan y ALBÁN Ernesto (2001): Historia de las Literaturas del Ecuador. Volumen 2. Quito, Universidad Andina Simón Bolívar, Corporación Editora Nacional.

VIEIRA, León (1988): “Juan Montalvo Profeta e Internacionalista”, en Visión Actual de Juan Montalvo. Quito, Ilustre Municipalidad de Ambato, Subsecretaría de Cultura, Fundación Friedrich Naumann, pp. 255-266 
VILLAVICENCIO, Augusto (1977): Historia del Ecuador. Segunda edición. Guayaquil-Ecuador.

VIVANCO, Jorge (2013): Alejandro Carrión: trabajador intelectual sin reposo: http://www.alejandrocarrion.org/periodismo\%20diners.html [fecha de consulta: 5 de julio del 2013] 